\title{
HIGH POTENTIALS AND HIGH PERFORMERS IN THE CENTER OF TALENT MANAGEMENT
}

\author{
Eszter Daruka ${ }^{1^{*}}$ and Katalin Pádár ${ }^{2}$ \\ ${ }^{1}$ Department of Management and Business Communication, Faculty of Economics and Business, \\ John von Neumann University, Hungary \\ 2 Department of Management and Business Communication, Faculty of Economics and Business, \\ John von Neumann University, Hungary \\ https://doi.org/10.47833/2020.2.ECO.004
}

\section{Keywords:}

High potential

High performer

Talent management

Human Resource Management

Literature review

\section{Article history:}

Received 5 November 2019

Revised 15 November 2019

Accepted 22 November 2019

\begin{abstract}
Talent management (TM) has become a key area in HRM in the recent years. In the center of any TM program, there are talented employees themselves, even though currently there are significant differences in approaches to talents within TM. Socalled talent tensions exist, for example, the object-subject, the exclusive-inclusive, the high potential-high performer, to name a few. In this work, the focus on the last tension with the following question to be answered: How often and in what way(s) are high potentials and high performers defined in the peer-reviewed TM literature. Therefore, as part of this systematic literature review, we examined 507 English-only articles and reviews published before December 31, 2018 in the Web of Science database containing the phrase 'talent management' in the topic field (Title, Abstract, Author Keywords, Keywords Plus®) to identify and analyze the conceptualizations of high potentials and high performers. The results show that a remarkable portion of TM articles are concentrating on high potentials and/or high performers, however, regarding the conceptualization, some differences are noticeable, which have significant effects on the operationalization and success of TM programs.
\end{abstract}

\section{Introduction}

During the past decades talent management (TM) has become a key area in HRM, so much so that some authors already claimed there to be a unique war, a 'War for Talent' [1]-[3]. As talents are in the center of TM, the operationalization of TM programs is inseparable from the conceptualization of talent, even though definitions and approaches to talents within TM differ significantly in current research works e.g., [4]-[7]. For example, so-called talent tensions are the object versus subject, the exclusive versus inclusive, and the high potential versus high performer approaches [8], to name a few.

This work is aimed to contribute to the development of the field of TM, and to help cease the inconsistencies about term 'talent' by examining talent definitions in the peer-reviewed TM literature. We focus on the high potential-high performer approaches with the following question to be answered: How often and in what way(s) are high potentials and high performers defined?

The article is structured as follows. We provide a brief literature review on the relevant talent approaches, then come a short description of the methodology of data collection and details about the analyzed data. Results of the analysis are followed by the conclusions.

\footnotetext{
* Corresponding author. Tel.: +36 307996621

E-mail address: daruka.eszter@gtk.uni-neumann.hu
} 


\section{Literature review}

In the work-related TM literature, several different conceptualizations, approaches and tensions can be found regarding talented employees, see for example: Dries [9], Gallardo-Gallardo, Dries, and González-Cruz [10], Gallardo-Gallardo, Dries, and González-Cruz [8], Gelens, Dries, Hofmans, and Pepermans [11], McCracken, Currie, and Harrison [12], Meyers, van Woerkom, and Dries [13], Meyers and van Woerkom [14], Nijs, Gallardo-Gallrado, Dries, and Sels [15], Tansley [16], Thunnissen et al. [6], and Thunnissen et al. [17]. Hereinafter, we briefly present the most relevant content concerning the goal of this paper.

In her work, Tansley [16] differentiated organizational, group, and individual levels of talent. From an exclusive aspect, 'talent as individual specific' can be conceptualized in following five ways certain expected behaviors, as a combination of high performance and high potential applying the nine-box grid, as high potential, as high performance, or as individual strengths. She defined a high potential employee as "...someone with the ability, engagement and aspiration to rise to and succeed in more senior, more critical positions. It can be useful to deconstruct the different elements in terms of ability, aspiration and engagement." [16, p. 272] Concerning high performance, the author emphasized that the required level of performance depends on the needs of the given organization and the nature of the work, and can be linked to other important characteristics that are most frequently associated with talented individuals, for instance, high levels of expertise, leadership behaviors, or creativity. [16]

In her often cited paper, Dries [9, pp. 275-280] identified 5 talent tensions: a) object (talent as characteristics of people) vs. subject (talent as people), b) inclusive (all people are talented) vs. exclusive (some people are more talented), c) innate vs. acquired (according to the extent to which talent can be taught and learned), d) input vs. output (showing whether talent depends more on motivation or ability), and e) transferable vs. context dependent (concerning the extent to which talent is conditional on its environment). High potential employees were classified into the subject approach—without any detailed explanation from the author.

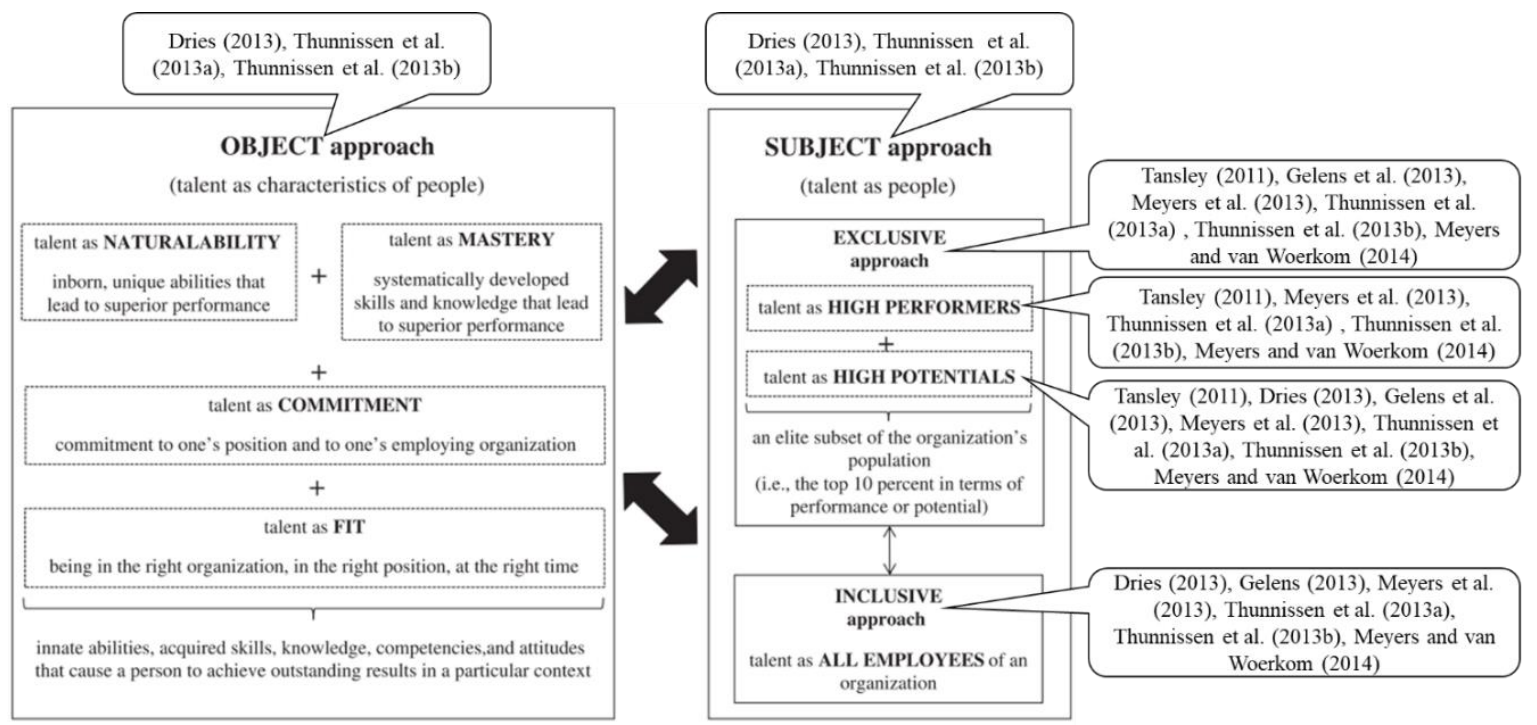

Figure 1. The summary of talent tensions and approaches in line with Gallardo-Gallardo et al.'s [8] 'Framework for the conceptualization of talent within the world of work'

Source: Gallardo-Gallardo et al. [8, p. 297] extended by the authors with examples from the literature

The well-known, work-related framework for defining talent by Gallardo-Gallardo et al. [8] was based on the object vs. subject tension. (Figure 1) On the one hand, within the object approach 4 sub-approaches were distinguished: talent as natural ability, talent as mastery, talent as commitment, and talent as fit. On the other hand, within the subject approach, the exclusive vs. inclusive tension was identified. According to the exclusive tension, talent can be defined as high performers and/or as high potentials, while all the employees of the given organization are talents 
within the inclusive approach. High performers were referred as "the best of class" or 'A players', too, and were defined "as the group of employees who rank at the top of capability and performance (Stahl et al., 2007)"; or who possess exceptional skills and abilities in a specific area, a specific competency, or a general area (Silzer and Dowell, 2010); or who "demonstrate exceptional ability and achievement in an array of activities and situations, or within a specialized field of expertise, on a regular basis (Williams, 2000)". [8, p. 295] High potential employees - in general, demonstrating high levels of potential - were defined as "those employees believed to have the potential to advance at a faster pace than their peers, whilst demonstrating different needs, motivations, and behaviors than 'regular' employees (Pepermans, Vloeberghs, \& Perkisas, 2003)" [8, p. 296]

Gelens et al. [11] were concerned about the inclusive vs. exclusive approaches to TM, furthermore, in connection to the latter, about workforce differentiation, as well. They defined talent from a human capital perspective based on the assessment of its value and uniqueness. In this viewpoint, those employees who are high on both value and uniqueness (i.e., talents) are often referred as high potentials. The authors cited 2 definitions of high potentials: those employees who "show potential to become something more than what they currently are (Silzer \& Church, 2009, p. 4)" and who are "recognized, at that point in time, as the organization's likely future leaders (Cope, 1998, p. 15)". [11, p. 342]

In Meyers et al.'s [13] work, beside the innate vs. acquired talent approaches, the exclusive vs. inclusive TM approaches are mentioned, as well. The former one is "directed at a small, elitist percentage of the workforce only-the high potential, highly performing, or strategically important employees (Boudreau \& Ramstad, 2005; Collings \& Mellahi, 2009)" [13, p. 306]. Among the theoretical talent approaches, talent as high potential, and talent as high performance also appeared-besides talent as giftedness, talent as individual strength, and talent as (meta-) competencies. The authors noted that it was challenging to clearly define high potentials. In their viewpoint [13, p. 308], "In contrast to the perspective that talent denotes potential or possibilities for the future, talent can also be understood as a construct that becomes manifest in present actions and behaviours, or, in short, performance (Altman, 1997). Talent in this regard is defined by realized outputs, and not, as in other approaches to talent, by the inputs that are necessary to achieve a certain output (e.g., knowledge, skills, and abilities)."

Regarding talent tensions, Thunnissen et al. [6] highlighted the subject vs. object approaches according to Gallardo-Gallardo et al. [10], and the inclusive vs. exclusive approaches supplementing them with the hybrid approach in line with Stahl et al. [7]. Pairing the subject vs. object and inclusive vs. exclusive approaches, they defined talent_among other versions-as the following: "The third interpretation of talent, the exclusive approach to talent as a subject, is based on segmentation or differentiation of a small segment of the workforce (Gallardo-Gallardo [et al.,] 2012). In this approach, talent refers to those employees who rank at the top in terms of capability and performance and who make a significant difference to the current and future performance of the organization (e.g. McCauley and Wakefield 2006; Stahl et al. 2007; Davies and Davies 2010; McDonnell 2011). These employees are often called A-players, high performers or high potentials." [6, pp. 1750-1751] The authors cited Gallardo-Gallardo et al.'s [10] criticism on the definition of talent through its output, as they were also on the opinion that high performance alone cannot be identified as talent.

Thunnissen et al. [17] shortly summarized the subject vs. object, and the inclusive vs. exclusive talent approaches according to Gallardo-Gallardo et al. [8], stating that "the exclusive-subject approach focuses on a select group of high-performing and/or high-potential employees" [17, $p$. 327] — without providing any further detailed explanation on the meaning of these expressions.

In their paper, Meyers and van Woerkom [14] presented 4 different talent philosophies according to the perception of talent as a) exclusive (rare with A players, high potentials, high performers, or strategically important employees) vs. inclusive (universal with all employees), and b) stable vs. developable-leading to exclusive/stable; exclusive/developable (encompassing high potential employees); inclusive/stable; and inclusive/developable talent philosophies. In line with the exclusive/developable talent philosophy, they emphasized the importance of workforce segmentation, and the significance of the identification and development of high potential employees. 


\section{Data, Methods, and Steps of the Analysis}

As this paper is aimed at examining how often and in what way(s) are high potentials and high performers defined as the subject(s) of TM, the authors collected all the relevant publications from the Web of Science (WoS) database. We searched for those items which contained the phrase "talent management" in the topic field (Title, Abstract, Author Keywords, Keywords Plus $®$ ); were published as articles, book chapters, proceedings papers, or reviews in English language before December 31, 2018; had a connection to HRM; and the full paper version was available. This query resulted in 507 publications which were examined to identify and analyze the conceptualizations of high potentials and high performers.

For the analysis, we collected all the explicit (expresses the meaning directly), general (noncontext specific or special type) definitions on the subject of TM manually, regardless whether they defined the term 'talent' or other concept(s). Context specific definitions were excluded from this work.

Then, regarding the identified definitions, we marked the definiens (the explanation part of the definition) and the definiendum/definienda (the concept(s) being defined). For example, in the following definition there are 4 definienda (marked in bold, while the definiens is highlighted in italics).

"...talent refers to those employees who rank at the top in terms of capability and performance and who make a significant difference to the current and future performance of the organization (e.g. McCauley and Wakefield 2006; Stahl et al. 2007; Davies and Davies 2010; McDonnell 2011). These employees are often called A-players, high performers or high potentials." [6, pp. 1750-1751], highlight ours

\section{Findings}

The results show that a remarkable portion of TM articles are concentrating on high potentials and/or high performers, however, regarding the conceptualization, some differences are noticeable, which may have significant effects on the operationalization and success of TM programs.

According to the results of the analysis, only 138 of 507 TM articles contained explicit, general definition(s) about the subject of TM. In these 138 articles, there were 363 definitions altogether.

Examining the 363 definitions in detail, we identified 425 definienda, as in 47 definitions, more definienda were defined at the same time. For example, A players and high potential talent appeared in the following definition [18, p. 274]: "Individuals identified as "A players" or "high-potential" talent are those employees identified as having potential to contribute strongly to future business performance (Collings and Mellahi, 2009; Lewis and Heckman, 2006)."

We found that notwithstanding that the term 'talent' dominated the 425 definienda with 302 occurrences (71\%), several other expressions were defined in 123 cases (29\%). In 45 out of these 123, the word 'talent' appeared in some kind of combination with other expressions as the definiendum, for instance, "highly talented individual" [19], "human talent" e.g., [20], "individual talent" [21], or "talented employee" e.g., [22].

Nevertheless, 78 further definienda were also identified that expressed the subject of TM, for example: "A player" e.g., [18], "high flyer" [23], or "star employee" [24]. As 70 out of these 78 belonged to the two approaches of the exclusive subject talent approach in line with the well-known framework of talent approaches by Gallardo-Gallardo et al. [8], the dominance of the exclusive subject talent approach was noticeable in these definienda. The occurrence of expressions referring to the 'talent as high performer' approach (40) was higher than the number of occurrences related to the 'talent as high potential' approach (29).

In 29 cases, "high potential" and "high potential employee" (HiPo) or a kind of synonym for these ("those with high potential") was defined. While in 40 cases, the definiendum ("high performer", "high performing employee", "high performing individual", "high flyer", "exceptional performer", "overachiever", "A player", "A grade", "A job", "star", "star employee", "superstar, "superkeeper") was in line with the 'talent as high performer' tension. In addition, in 1 case, both of these tensions appeared in the given definiendum (such as "high performance and high potential").

Moreover, in 2 cases, we found examples (such as "expert", and "valuable contributor") for the 'talent as mastery' tension within the object approach. Interestingly, we also found 4 examples for the inclusive subject approach: the terms human capital or people were used interchangeably with 
talent as definienda. Furthermore, in 2 definitions, besides talent, pivotal roles were also defined as the subjects of TM. Such a definiendum is in line with the exclusive TM approach by Gelens et al. [11] and by Meyers et al. [13], however, it cannot be categorized into the framework of GallardoGallardo et al. [8].

In order to examine the definientia, we separated the definitions according to the definienda. We found that 39 definitions contained those 70 aforementioned definienda which were in line with the high potential or high performer tensions. We further analyzed those 324 definitions in detail which did not define any concepts in line with the high potential or high performer tensions.

We found that 86 out of these 324 definientia (26\%) conceptualized talent in line with the high potential talent approach, the high performer talent approach appeared in 55 definientia (17\%), while 74 definientia (23\%) were in accordance with both of these two exclusive talent tensions. (Figure 2) Thus, the notions of the high potential and high performer approaches were present altogether in 215 out of these 324 definientia (66\%). A further 109 definientia (34\%) were based on other talent approaches.

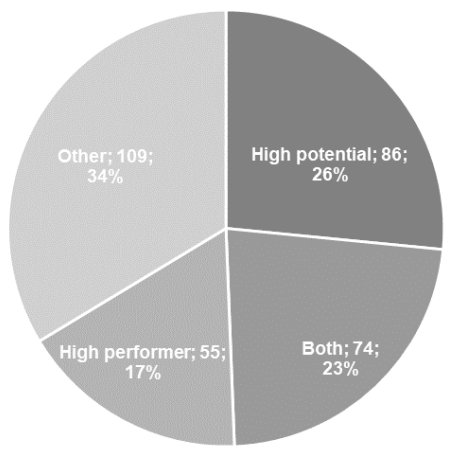

Figure 2. Ratio of the high potential and high performer talent approaches appearing in the definientia of explicit definitions of the subject(s) of TM

Source: Authors' own work

To sum up, the analysis of the explicit comprehensive definitions on the subject of TM in the 507 articles resulted in the finding that beyond 'talent', several other expressions were also conceptualized in the examined TM articles. This makes it quite hard to identify and to collate the different conceptualizations. The results revealed that the 'talent as high potential' and 'talent as high performer' approaches appeared in 70 out of the 425 definienda, and in 215 out of the 324 definientia. It can be said that these approaches played a central role in defining the subjects of TM.

\section{Conclusions}

In this work, we focused on the direct definitions on the subject of TM in peer-reviewed articles. The analysis showed that only 138 out of the examined 507 publications contained explicit comprehensive definition(s). In these 138 TM publications, 363 explicit general definitions were identified on the subject of TM-resulting in an average of more than 2 definitions per article.

In the 363 definitions on the subject of TM, we found 425 definienda (i.e., at times more concepts were defined in a given definition). Beyond talent (302 times), several other expressions appeared; 78 cases did not contain the term 'talent' at all. We recognized the dominance of the exclusive subject talent approach in these 'other' definienda-only 8 out of the 78 were not in line with the talent as high potential and/or talent as high performer approaches. Examining the definientia in detail, we found that in the vast majority $(66 \%)$ of them the notions of the high potential or high performer approaches, or both of them, were present.

As our analysis pointed out, the high potential and high performer tensions play a central role in defining the subjects of TM, but several different expressions were defined as the subjects of TM in the examined articles. Due to the differences, however, it is not so easy to collect, classify, or compare these conceptualizations to each other. Although, it might be very useful in order to build and operationalize any formal TM program. In the future, it would be worth examining all the collected definitions, and summarizing the features of the indirect and context/corporate specific conceptualizations on the subject of TM, as well as, the special talent type definitions. 


\section{References}

[1] E. G. Chambers, M. Foulon, H. Handfield-Jones, S. M. Hankin, and E. Michaels, "The War for Talent," McKinsey Q., vol. 3, no. 3, pp. 44-57, 1998.

[2] E. Michaels, H. Handfield-Jones, and B. Axelrod, The War for Talent. Boston, MA: Harvard Business School Press, 2001.

[3] B. Axelrod, H. Handfield-Jones, and E. Michaels, "A new plan for C players," Harv. Bus. Rev., vol. 80, no. 1, pp. 81-88, 2002.

[4] M. Höglund, "Quid pro quo? Examining talent management through the lens of psychological contracts," Pers. Rev., vol. 41, no. 2, pp. 126-142, Feb. 2012.

[5] R. E. Lewis and R. J. Heckman, "Talent management: A critical review," Hum. Resour. Manag. Rev., vol. 16, no. 2, pp. 139-154, 2006.

[6] M. Thunnissen, P. Boselie, and B. Fruytier, "A review of talent management: 'infancy or adolescence?,"' Int. J. Hum. Resour. Manag., vol. 24, no. 9, pp. 1744-1761, May 2013.

[7] G. K. Stahl et al., "Six Principles of Effective Global Talent Management," MIT Sloan Manag. Rev., vol. 53, no. 2, pp. 24-33, 2012.

[8] E. Gallardo-Gallardo, N. Dries, and T. F. González-Cruz, "What is the meaning of 'talent' in the world of work?," Hum. Resour. Manag. Rev., vol. 23, no. 4, pp. 290-300, Dec. 2013.

[9] N. Dries, "The psychology of talent management: A review and research agenda," Hum. Resour. Manag. Rev., vol. 23, no. 4, pp. 272-285, Dec. 2013.

[10] E. Gallardo-Gallardo, N. Dries, and T. F. Gonzalez-Cruz, "What Do We Actually Mean by Talent in Business?" 1st EIASM Workshop on Talent Management, Brussels, Belgium, 2012.

[11] J. Gelens, N. Dries, J. Hofmans, and R. Pepermans, "The role of perceived organizational justice in shaping the outcomes of talent management: A research agenda," Hum. Resour. Manag. Rev., vol. 23, no. 4, pp. 341-353, Dec. 2013.

[12] M. McCracken, D. Currie, and J. Harrison, "Understanding graduate recruitment, development and retention for the enhancement of talent management: sharpening 'the edge' of graduate talent," Int. J. Hum. Resour. Manag., vol. 27, no. 22, pp. 2727-2752, Dec. 2016.

[13] M. C. Meyers, M. van Woerkom, and N. Dries, "Talent - Innate or acquired? Theoretical considerations and their implications for talent management," Hum. Resour. Manag. Rev., vol. 23, no. 4, pp. 305-321, Dec. 2013.

[14] M. C. Meyers and M. van Woerkom, "The influence of underlying philosophies on talent management: Theory, implications for practice, and research agenda," J. World Bus., vol. 49, no. 2, pp. 192-203, Apr. 2014.

[15] S. Nijs, E. Gallardo-Gallardo, N. Dries, and L. Sels, "A multidisciplinary review into the definition, operationalization, and measurement of talent," J. World Bus., vol. 49, no. 2, pp. 180-191, Apr. 2014.

[16] C. Tansley, "What do we mean by the term 'talent' in talent management?," Ind. Commer. Train., vol. 43, no. 5, pp. 266-274, Jul. 2011.

[17] M. Thunnissen, P. Boselie, and B. Fruytier, "Talent management and the relevance of context: Towards a pluralistic approach," Hum. Resour. Manag. Rev., vol. 23, no. 4, pp. 326-336, Dec. 2013.

[18] K. A. King, "Global talent management," J. Glob. Mobil., vol. 3, no. 3, pp. 273-288, Sep. 2015.

[19] R. S. Schuler, S. E. Jackson, and I. Tarique, "Global talent management and global talent challenges: Strategic opportunities for IHRM,” J. World Bus., vol. 46, no. 4, pp. 506-516, Oct. 2011.

[20] M. M. Tafti, M. Mahmoudsalehi, and M. Amiri, "Critical success factors, challenges and obstacles in talent management," Ind. Commer. Train., vol. 49, no. 1, pp. 15-21, Jan. 2017.

[21] P. van Heugten, M. Heijne-Penninga, W. Paans, and M. Wolfensberger, "Characteristics of highly talented international business professionals defined," Eur. J. Train. Dev., vol. 40, no. 2, pp. 58-73, Feb. 2016.

[22] M. O. Latukha, "Can Talent Management Practices Be Considered as a Basis for Sustainable Competitive Advantages in Emerging-Market Firms? Evidence from Russia," Thunderbird Int. Bus. Rev., vol. 60, no. 1, pp. 69-87, Jan. 2018.

[23] J. K. Mensah, "A 'coalesced framework' of talent management and employee performance," Int. J. Product. Perform. Manag., vol. 64, no. 4, pp. 544-566, Apr. 2015.

[24] A. Savanevičienè and B. Vilčiauskaitè, "Practical Application of Exclusive and Inclusive Talent Management Strategy in Companies," Business, Manag. Educ., vol. 15, no. 2, pp. 242-260, Dec. 2017. 